\title{
Efficacy and Safety of Imatinib in Paediatric CML - A Single Centre Study
}

\author{
CYNTHIA SMEDING ${ }^{1}$, ALEKSANDRA SZYDŁO $^{1}$, KRZYSZTOF PIELUSZCZAK $^{1}$, \\ KATARZYNA GRZESZKIEWICZ ${ }^{2}$ and KATARZYNA PAWELEC ${ }^{2}$ \\ ${ }^{1}$ Student Scientific Group 'SPHEROCYTE', Department of Paediatric Haematology and Oncology, \\ Medical University of Warsaw, Warsaw, Poland; \\ ${ }^{2}$ Department of Paediatric Haematology and Oncology, Medical University of Warsaw, Warsaw, Poland
}

\begin{abstract}
Background/Aim: Chronic myeloid leukaemia $(C M L)$ rarely affects the paediatric population and has an incidence of 0.06-0.12/100,000 children per year. The dire clinical course of paediatric CML is further exacerbated by the adverse effects of long-term imatinib therapy. Patients and Methods: Our cohort comprised 14 CML patients who were treated with imatinib between July 2010 and September 2018. The European Leukaemia Net (ELN) standard milestones of response criteria were used to evaluate its therapeutic effectiveness. Results: Complete haematological remission and partial cytogenetic response were achieved in all patients. Complete cytogenetic response was achieved in seven patients. Major molecular response was achieved in six patients. Two patients underwent haematopoietic stem cell transplantation due to unsatisfactory response to imatinib. Conclusion: Imatinib is effective in treating paediatric CML and limits the progression to advanced stages, however, the quality of life still needs to be optimised.
\end{abstract}

Chronic myeloid leukaemia (CML) rarely affects the paediatric population and has an estimated incidence of 0.06 0.12 per 100,000 children per year (1). The tyrosine kinase inhibitor (TKI) therapy improves the overall and event-free survival (EFS) rates in paediatric CML (2). Imatinib, a firstgeneration TKI, is proposed as the first-line therapy for improved effectiveness (3). CML presents, within paediatric

This article is freely accessible online.

Correspondence to: Katarzyna Pawelec MD, Ph.D., Department of Paediatric Haematology and Oncology, Public Paediatric Teaching Clinical Hospital, Medical University of Warsaw, Żwirki i Wigury 63A, 02-091 Warsaw, Poland. Tel: +48 605645005, Fax: +48 223179622, e-mail: katarzyna.pawelec@litewska.edu.pl

Key Words: BCR-ABL1, children, adolescents, chronic myeloid leukaemia, imatinib. patients, with a clinically more aggressive course compared to that of adults, and is further exacerbated by several longterm side effects of imatinib (4). A potential resistance to the drug due to mutations in the BCR-ABL1 gene may significantly limit its effectiveness, rendering the evaluation of severity and management of the disease exceedingly challenging (5). Knowledge on the definite efficacy and safety of imatinib treatment within the paediatric population is scarce. The aim of this retrospective observational study was to assess the safety of long-term administration in terms of adverse effects from the use of imatinib in paediatric CML patients, as well as to estimate the probability of progression to advanced stages of the disease.

\section{Patients and Methods}

Patients. Our cohort included 14 patients (males, $\mathrm{n}=12$; females, $\mathrm{n}=2$ ) who were diagnosed with BCR-ABL1 positive CML and were treated with imatinib between July 2010 and September 2018 at the Department of Paediatric, Haematology and Oncology at the Medical University of Warsaw, Poland (Table I).

Diagnosis. Diagnosis was based upon the mandatory identification of the BCR-ABL1 fusion gene mutation in accordance with the 4th edition of the World Health Organisation recommendations (6). All CML patients under 18 years of age who received imatinib as a first-line therapy upon diagnosis were included into our study. The evaluation of therapeutic effectiveness ensued from using the standard mile-stones of response established by the European Leukaemia Net (ELN) (7). Complete haematological remission (CHR) was assigned within the first 3 months of therapy whereas partial and complete cytogenetic responses (CCyR and PCyR, respectively) were set on the 12th month of treatment. Major molecular response (MMR) was set to be achieved by the 18th month of treatment. CHR was defined when full leukocyte count was under $10 \times 10^{9} / \mathrm{L}$ without promyelocytes, myelocytes or blasts in peripheral blood, including $<5 \%$ basophil and a platelet count under $450 \times 10^{9} / \mathrm{L}$. No splenomegaly should have been observed upon physical examination. Cytogenetic response was categorized as partial if $1-35 \% \mathrm{Ph}(+)$ mitosis was detected in the bone marrow and as complete in the absence of $\mathrm{Ph}(+)$ cells using FISH analysis. 
Table I. Clinical characteristics of patients $(n=14)$ upon admission.

\begin{tabular}{lc}
\hline Study cohort & \\
\hline Age (years) & \\
Median/Mean & $9.8 / 9.7$ \\
Range & $1.3-16.9$ \\
Gender $(\mathrm{n})$ & \\
Male & $12(86 \%)$ \\
Female & $2(14 \%)$ \\
Splenomegaly (cm below costal margin) & \\
Yes (n) & $11(79 \%)$ \\
Median/Mean & $5 / 7.6$ \\
Range & $1.5-17$ \\
No $(\mathrm{n})$ & $3(21 \%)$ \\
Leukocytes $\left(\times 10^{9} / \mathrm{L}\right)$ & \\
Median/Mean & $170.5 / 199$ \\
Range & $23-582$ \\
Haemoglobin level $(\mathrm{g} / \mathrm{dL})$ & \\
Median/Mean & $9.45 / 10.1$ \\
Range & $6-13.8$ \\
Platelets $\left(\times 10^{9} / \mathrm{L}\right)$ & \\
Median/Mean & $455 / 641$ \\
Range & $260-2743$ \\
\hline
\end{tabular}

Molecular response was defined as major if BCR-ABL1 transcript level measured below $0.1 \%$ upon quantitative real-time reverse polymerase chain reaction. In addition, clinical data on patient demographics, presenting complaints, imatinib dosage, duration of treatment, encountered adverse effects of treatment and outcome were recorded. The inclusion of additional pharmacologic agents (e.g. hydroxyurea, cytarabine) in addition to imatinib therapy, were also taken into account for data processing and prognosis evaluation. Height, weight and serum vitamin $\mathrm{D}_{3}$ levels were watchfully monitored during the entire course of imatinib intake.

Statistics. The STATISTICA v. 13.3 software package was used for all statistical analyses. Continuous variables were expressed as a median (+range). Categorical variables were expressed as numerical values with their corresponding percentage. Patients were divided into pre-pubertal $(n=7)$ and intra-pubertal groups $(n=7)$. The parametric $t$ test was applied to ascertain CHR. Fisher's exact test was applied to assess achievement of CCyR and MMR. Statistical significance was defined as $p<0.05$.

Retrospective studies conducted at our institution do not require approval by the bioethical committee.

\section{Results}

The median age upon diagnosis was 9.7 years (range $=1.3-16.9$ years). At admission, 13 patients were diagnosed in the chronic phase of the disease whereas one patient was in the accelerated phase. The encountered complaints upon presentation prior to diagnosis are presented in Table II. Hyperleukocytosis was observed in 10 patients (median leukocyte count was $171 \times 10^{9} / \mathrm{L}$; range $=23-582 \times 10^{9} / \mathrm{L}$ ), thrombocytosis was found in 4 patients (median thrombocyte
Table II. Presenting signs and symptoms prior to diagnosis.

\begin{tabular}{lc}
\hline Signs and symptoms on admission & Patients $(\mathrm{n})$ \\
\hline Splenomegaly & 11 \\
Hepatomegaly & 10 \\
Hyperleukocytosis $\left(>700^{*} 10^{9} / \mathrm{L}\right)$ & 10 \\
Asthaenia & 6 \\
Abdominal pain & 5 \\
Thrombocytosis $\left(>450^{*} 10^{9} / \mathrm{L}\right)$ & 4 \\
Haemorrhage & 3 \\
Bone pain & 3 \\
Priapism & 2 \\
Weight loss & 2 \\
Fever & 2 \\
Lymphadenopathy & 2 \\
Anaemia & 2 \\
Pallor & 2 \\
Acne & 1 \\
Papular rash & 1 \\
Ecchymoses & 1 \\
Coagulopathy & 1 \\
Dyspnoea & 1 \\
Fixed hip and knee joints & 1 \\
\hline
\end{tabular}

count was $455 \times 10^{9} / 1$; range $\left.=260-2743 \times 10^{9} / 1\right)$ and anaemia was encountered merely in 2 patients (median haemoglobin was $9.5 \mathrm{~g} / \mathrm{dl}$, range $=6-13.8 \mathrm{~g} / \mathrm{dl}$ ). The most commonly encountered initial dose of imatinib was $300 \mathrm{mg} / \mathrm{m}^{2}(\mathrm{n}=12)$. The maximal and minimal doses of initiation were $350 \mathrm{mg} / \mathrm{m}^{2}$ $(\mathrm{n}=1)$ and $150 \mathrm{mg} / \mathrm{m}^{2}(\mathrm{n}=1)$, respectively. The maximal dose during treatment was $500 \mathrm{mg} / \mathrm{m}^{2}(\mathrm{n}=2)$. One patient received two additional drugs in the regimen in addition to imatinib, hydroxyurea $\left(1,000 \mathrm{mg} / \mathrm{m}^{2} /\right.$ day for 14 days $)$ and cytarabine $\left(28 \mathrm{mg} / \mathrm{m}^{2} /\right.$ day for 10 days), due to severe non-subsiding symptoms of hyperleukocytosis (dyspnoea and disturbances of consciousness). The median time from diagnosis till onset of treatment was 2 days (range $=0-7$ days). Throughout therapy, the dose had to be modified in a total of 9 patients. An increased dose was applied to 3 patients due to lack of a satisfactory response. A reduced dose was encountered in 6 patients due to symptoms of toxicity; bone pain $(n=6)$, vomiting $(n=5)$, neutropenia $(n=1)$, leukopenia $(n=1)$, headache $(n=1)$. Table III presents all imatinib side effects encountered in our study. The median follow-up time was 23,5 months. Figure 1 presents the results of the cumulative incidence of responses to treatment. CHR and PCyR were achieved in all patients. The median time of accomplishing CCyR was 356 days (range=97-910 days). Three patients had CCyR relapse. MMR was achieved in an additional 3 patients after 20 months $(n=2)$ and 23 months $(n=1)$. One patient had MMR relapse. The results of treatment with imatinib are presented in Table IV. The mean CHR for the pre-pubertal and intra-pubertal groups were 45 days and 78 days, respectively 


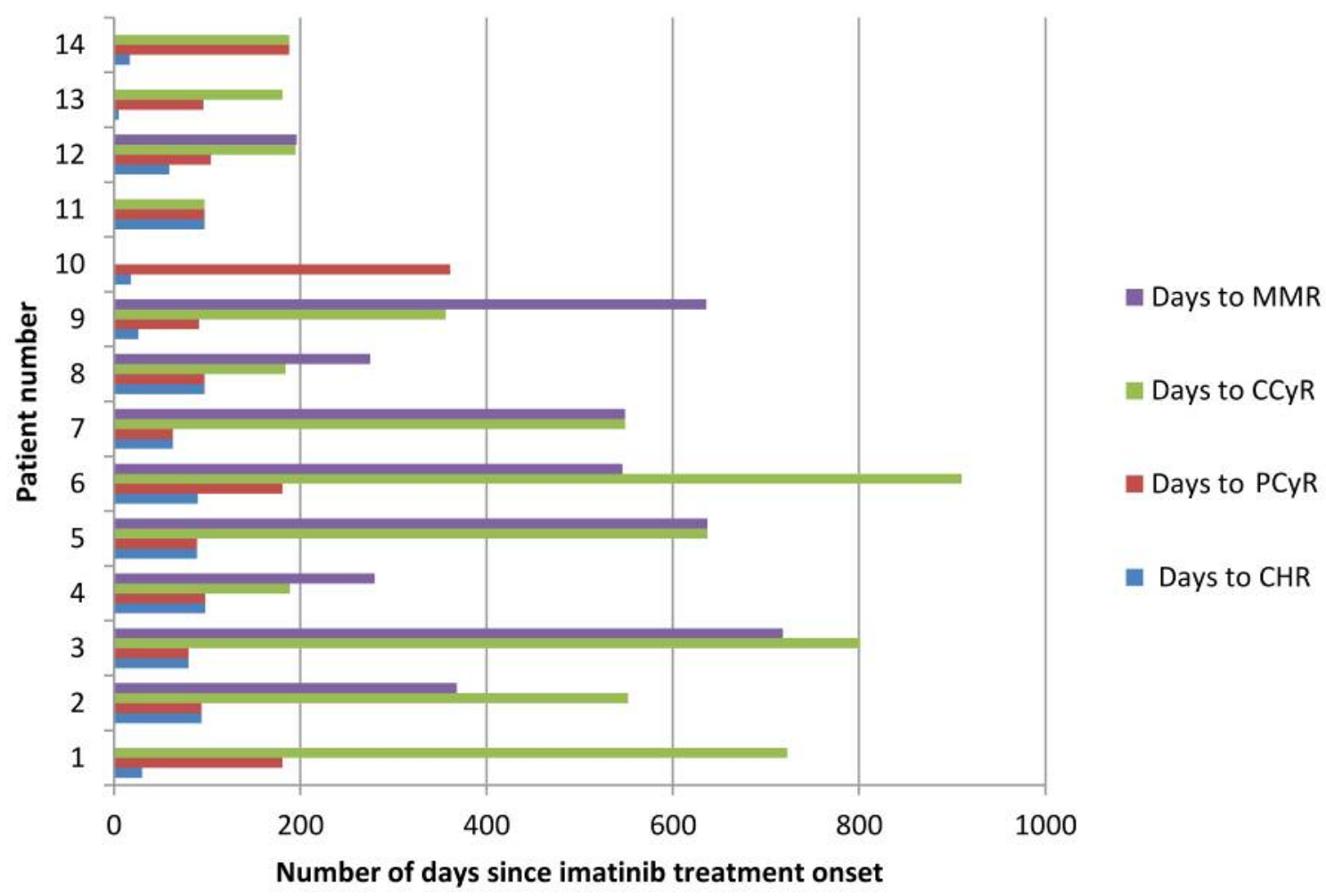

Figure 1. Cumulative incidence of response. MMR: Major molecular response; CCyR: complete cytogenetic response; PCyR: partial cytogenetic response; CHR: complete haematologic remission.

Table III. Observed adverse effects due to imatinib therapy.

\begin{tabular}{lcc}
\hline Side effects of Imatinib & \multicolumn{2}{c}{ Patients } \\
\cline { 2 - 3 } & $(\mathrm{n})$ & $(\%)$ \\
\hline Nausea & 2 & 14 \\
Vomiting & 5 & 36 \\
Diarrhoea & 2 & 14 \\
Liver toxicity & 1 & 7 \\
Muscle cramps or pains & 2 & 14 \\
Bone, joint or tendon pains & 7 & 50 \\
Legg-Calve-Perthes disease & 1 & 7 \\
Anaemia & 1 & 7 \\
Neutropenia & 1 & 7 \\
Papular rash & 1 & 7 \\
Headache & 1 & 7 \\
Toothache & 1 & 7 \\
Jaw tingling & 1 & 7 \\
Gynecomastia & 1 & 7 \\
Paraesthesiae & 1 & 7 \\
\hline
\end{tabular}

$(p=0.08)$. No statistical significance was attained for CCyR and MMR in either pre- or intra-pubertal groups. In total, 5 patients did not achieve MMR, 4 of whom did not complete the 18 months follow-up; 2 of those patients transitioned into
Table IV. Results of imatinib treatment.

\begin{tabular}{lc}
\hline Study group & Patients (n) \\
\hline Phase at the diagnosis & \\
Chronic phase & $13(93 \%)$ \\
Accelerated phase & $1(7 \%)$ \\
Complete haematologic remission & \\
Within 3 months & $14(100 \%)$ \\
Complete cytogenetic response & $7(50 \%)$ \\
Within 12 months & $7(50 \%)$ \\
After 12 months & $1(7 \%)$ \\
Failure of achievement & \\
Major molecular response & $6(43 \%)$ \\
Within 18 months & $3(21 \%)$ \\
After 18 months & $4(29 \%)$ \\
Failure of achievement & $9(64 \%)$ \\
Modification of imatinib dose & $3(21 \%)$ \\
Increase & $6(43 \%)$ \\
Decrease & $2(14 \%)$ \\
Haematopoietic stem cell transplantation &
\end{tabular}

adulthood while the other 2 patients are under continued imatinib therapy. Resistance to imatinib was encountered in 2 patients, one from the pre-pubertal and one from the intrapubertal group. A total of 10 patients are still under 
supervision in our clinic until the completion of this study; 8 of these patients are still on imatinib treatment while the other 2 were qualified for and have gone through haematopoietic stem cell transplantation (HSCT), due to unsuccessful response to imatinib. Four patients were not followed-up due to transition into adulthood. All patients enrolled in our study were compliant to imatinib intake and none switched to second generation TKIs. No deaths were reported in our study.

\section{Discussion}

Since the onset of the new millennium, TKIs have markedly improved the overall and event-free survival rates of paediatric CML patients (2). Multiple trials have confirmed that first-line imatinib is highly effective in newly diagnosed paediatric CML, protecting these patients from being exposed to the life-threatening risks associated with HSCT (3). The largest retrospective cohort study conducted in the paediatric age group included a total of 238 cases. The authors found that hyperleukocytosis is not a prognostic factor in the 5-year EFS, as the EFS was $93.3 \%$ in patients presenting with hyperleukocytosis, in contrast to those without hyperleukocytosis (82.0\%) (8). A recent study conducted by Shima et al., revealed that flow cytometric analysis of bone marrow (BM) in children with chronicphase CML is a useful tool for predicting the treatment responses of imatinib. If during the first 3 months of imatinib treatment, there is predominance of granulocyte macrophage progenitors and sustained expression of the myeloproliferative leukaemia virus oncogene stem cellrelated marker in $\mathrm{BM}$ progenitors, then there is a poor prognosis for these children with chronic-phase CML (9).

Adhering to the treatment regimen is key to imatinib's success in paediatric CML. Our results showed that all our patients were compliant to treatment. Compliance, specifically during the chronic phase, clearly allows for an effective cytogenetic response favouring a better lifelong prognosis. Therefore, compliance should be regarded as a vital factor for the long-term beneficiary outcome of paediatric CML. An optimal cytogenetic response is attained at the end of 6 months in regimen-compliant children (10). As adherence to imatinib intake is the most important factor in predicting prognosis, it is imperative that the pubertal age group is under rigorous drug intake monitoring (11).

The longest exposure to imatinib treatment with accomplished CCyR documented in our study lasted 30 months and the longest follow-up was 66 months. While the sustained imatinib treatment can effectively control the disease, it is important to maintain a high quality of life of paediatric CML patients to counteract its life-long side effects. The suggested optimal care should include effective disease control without the need for daily medication intake. The latter ostensibly decreases the availability of therapy compliant patients within this critical age group, not to mention the undesirable side effects of a lifelong cTKI use that may further lower the quality of life, in the context of these children's longevity (7). As growth hormone secretion is potentially inhibited while on imatinib therapy, a disturbance of the osseous remodelling process is induced which markedly limits the attained impairment of longitudinal growth (11). Therefore, it remains crucial that the paediatric age group is alertly monitored while under a continuous imatinib treatment, at least during the first years and in terms of growth rate. Regardless of gender or pubertal age, a significant growth deceleration can be observed in all children (12). The most frequent complaint identified in our study involved pain in bones, joints or tendons ( $50 \%$ of patients), while we came across a more complicated case where the patient also suffered from Legg-Calvé-Perthes disease. Prolonged imatinib treatment is associated with significantly diminished vitamin $\mathrm{D}_{3}$ synthesis (13) leading to low bone mineral density, which may effectively mask other relevant bone parameters. For this reason, there is an urgent need for monitoring vitamin D3 levels in paediatric patients under continuous imatinib treatment (14). All our patients were carefully monitored for vitamin D3 deficiency. Numerous prospective trials on the withdrawal of imatinib, after having confirmed a deep molecular response, suggest that an attempt to subside from imatinib should be made after 24 months of treatment with consistent monitoring (15-17). In cases where real-time polymerase chain reaction results show an increase by at least one log on two consecutive measurements, imatinib treatment should, however, be sustained (18). Based on the results of aforementioned trials and our study findings, our standard clinical procedure is to discontinue imatinib treatment after achieving and maintaining MMR for 24 months, as a future prospect. The long-term follow-up of the STIM1 study confirms that imatinib discontinuation in adults is safe (18). However, as has been suggested by Suttorp et al., a paediatric prospective "stop imatinib" trial is merited to confirm the efficiency of this approach (11). A successful discontinuation of TKI therapy will reduce the long-term adverse effects associated with it. The risk factors for early molecular relapse should, nevertheless, be investigated (19).

The temporary inclusion of hydroxyurea and cytarabine in addition to imatinib in one patient of our study successfully eliminated the symptoms of hyperleukocytosis and effectively reduced the leukocyte count to normal levels. Pulse dosage administration of hydroxyurea effectively controls an excessive rise in white blood cells, whereas cytarabine has a contributing effect to imatinib in treating the chronic phase of CML and can potentially achieve a high rate of complete molecular response $(20,21)$.

Two patients in our study presented with priapism and splenomegaly along with hyperleukocytosis. A high index of suspicion in paediatric CML should be raised when 
encountering patients presenting with this urologic emergency in the presence of splenomegaly (22). Nontypical clinical signs further accentuate the already dire prognosis of paediatric CML, delaying its diagnosis as well as the treatment initiation. A full blood count with peripheral film examination should support the diagnosis. Leukapheresis should be ensued, in a time-efficient manner, for the safe and efficient management of the life-threatening complications of hyperleukocytosis (23). A case series by Catagnetti et al. found that a conservative approach to treating priapism in leukaemia patients prevents long-term impotence (24). A combined approach of therapeutic leukapheresis and a TKI is effective in reducing leukocyte counts in hyperleukocytosis with associated priapism (25).

Massive splenomegaly $(>10 \mathrm{~cm})$ with increased total leukocyte and platelet counts are a common finding in paediatric CML patients (19). A measurement of massive splenomegaly correlated to age could possibly reveal more information on the prognosis of these patients (26). It seems that the optimal treatment could yield a shorter time of the therapeutic TKI period and a reduction of long-term adverse effects due to TKI therapy. An improved conditioning regimen of allogeneic-HSCT with reduced-intensity stem cell transplantation could minimize the post-transplant mortality (19). Since CML remains a rare, but also a debilitating disease in the paediatric population, guidelines for treating paediatric CML need to be continuously optimized and incorporate the therapeutic experience stemming from adult CML (27). Clinical experience from the adult population may guide the therapeutic decision making process, however, care should be taken in terms of drug formulation, pharmacokinetics and compliance when applying the treatment to the fragile paediatric age group (28).

Currently, the only alternative to avoiding a lifelong exposure to TKI treatment is the aggressive eradication of CML stem cells along with intensive regimens of chemotherapy and TKIs of limited duration. As of today, HSCT in paediatric CML is only indicated when CML takes a recurrent and progressive course (29), and this cures paediatric CML inconsistently, whereas imatinib only suppresses the disease (2). As the costs associated with HSCT are minor compared to life-long imatinib therapy, HSCT seems to be a preferred option for younger patients, however it should be considered as a last resort treatment for pre-pubertal children (2). A global protocol and registry for paediatric CML allows for an optimal approach, especially since knowledge on TKI absorption and its metabolism remains poorly understood due to the rarity of this malignancy. HSCT should be primarily reserved for patients in the accelerated phase or in a blast crisis of CML and those unresponsive to TKI therapy (28).

Imatinib is an effective drug for the treatment of paediatric CML, limiting the progression of the condition to advanced stages, however, methods for improving the quality of life in paediatric patients that are on imatinib still need to be optimised. Further investigations are warranted for predicting the prognosis and the progression to advanced stages of paediatric CML. There is an urgent need for more multicentre studies to optimize the standardized management guidelines for treating CML with imatinib, while simultaneously maintaining a high quality of life in the fragile paediatric age group.

\section{Conflicts of Interest}

The Authors declare no conflicts of interest.

\section{Authors' Contributions}

Cynthia Smeding: data collection, analysis and interpretation of results, statistical analyses, construction of a figure, editing and writing of the original manuscript; Aleksandra Szydło: data collection, data calculations, writing of the manuscript; Krzysztof Pieluszczak: data collection, data calculations, construction of tables, writing of manuscript; Katarzyna Grzeszkiewicz: contribution to study design and data collection, writing of manuscript; Katarzyna Pawelec: study concept and design, supervision of the project, critical revision of the manuscript.

\section{Acknowledgments}

The Authors declare no funds or financial support was received for conceiving and completing this study.

\section{References}

1 de la Fuente J, Baruchel A, Biondi A, de Bont E, Dresse MF, Suttorp $\mathrm{M}$ and Millot F: Managing children with chronic myeloid leukaemia (CML): recommendations for the management of CML in children and young people up to the age of 18 years. Br J Haematol 167(1): 33-47, 2014. PMID: 24976289, doi: 10.1111/bjh.12977

2 Janeczko-Czarnecka M, Krawczuk-Rybak M, Karpińska-Derda I, Niedźwiecki M, Musioł K, Ćwiklińska M, Drabko K, Mycko $\mathrm{K}$, Ociepa T, Pawelec K, Januszkiewicz-Lewandowska D, Ussowicz M, Rybka B, Ryczan-Krawczyk R, Kołtan A, Karolczyk G, Zaucha-Prażmo A, Badowska W and Kałwak K: Imatinib in the treatment of chronic myeloid leukaemia in children and adolescents is effective and well tolerated: Report of the Polish Paediatric Study Group for the Treatment of Leukaemias and Lymphomas. Adv Clin Exp Med 27(1): 91-98, 2018. PMID: 29521048, doi: 10.17219/acem/66462

3 Suttorp M, Schulze P, Glauche I, Göhring G, von Neuhoff N, Metzler M, Sedlacek P, de Bont ESJM, Balduzzi A, Lausen B, Aleinikova O, Sufliarska S, Henze G, Strauss G, Eggert A, Kremens B, Groll AH, Berthold F, Klein C, Groß-Wieltsch U, Sykora KW, Borkhardt A, Kulozik AE, Schrappe M, Nowasz C, Krumbholz M, Tauer JT, Claviez A, Harbott J, Kreipe HH, Schlegelberger B and Thiede C: Front-line imatinib treatment in children and adolescents with chronic myeloid leukaemia: results from a phase III trial. Leukaemia 32(7): 1657-1669, 2018. PMID: 29925908, doi: 10.1038/s41375-018-0179-9 
4 Flynn KE and Atallah E: Quality of life and long-term therapy in patients with chronic myeloid leukaemia. Curr Hematol Malig Rep 11(2): 80-85, 2016. PMID: 26879546, doi: 10.1007/s11899016-0306-5

5 Hughes TP, Saglio G, Quintás-Cardama A, Mauro MJ, Kim DW, Lipton JH, Bradley-Garelik MB, Ukropec J and Hochhaus A: BCR-ABL1 mutation development during first-line treatment with dasatinib or imatinib for chronic myeloid leukemia in chronic phase. Leukemia 29(9): 1832-1838, 2015. PMID: 26118315, doi: 10.1038/leu.2015.168

6 Swerdlow SH, Campo E, Harris NL, Jaffe ES, Pileri SA, Stein $\mathrm{H}$ and Thiele $\mathrm{J}$ : WHO classification of Tumours of Haematopoietic and Lymphoid Tissues. Lyon: International Agency for Research on Cancer, pp. 35, 2017.

7 European Leukemia Net n.d. https://www.leukemia-net.org/ content/home/index_eng.html [Accessed December 9th, 2018].

8 Kurosawa H, Tanizawa A, Tono C, Watanabe A, Shima H, Ito M, Yuza Y, Hotta N, Muramatsu H, Okada M, Kajiwara R, Moriya Saito A, Mizutani S, Adachi S, Horibe K, Ishii E and Shimada H: Leukostasis in children and adolescents with chronic myeloid leukaemia: Japanese paediatric leukaemia/lymphoma study group. Pediatr Blood Cancer 63(3): 406-411, 2016. PMID: 26485422, doi: $10.1002 /$ pbc. 25803

9 Shima H, Kiyokawa N, Miharu M, Tanizawa A, Kurosawa H, Watanabe A, Ito M, Tono C, Yuza Y, Muramatsu H, Hotta N, Okada M, Hamamoto K, Kajiwara R, Saito AM, Horibe K, Mizutani S, Adachi S, Ishii E and Shimada H: Flow cytometric analysis as an additional predictive tool of treatment response in children with chronic-phase chronic myeloid leukaemia treated with imatinib. Pediatr Blood Cancer 64(9): 2017. PMID: 28233439, doi: 10.1002/pbc.26478

10 Ganta RR, Nasaka S and Gundeti S: Impact of imatinib adherence on the cytogenetic response in paediatric chronic myeloid leukaemia - chronic phase. Indian J Pediatr 83(9): 10091012, 2016. PMID: 26843266, doi: 10.1007/s12098-015-2007-9

11 Suttorp M, Bornhäuser M, Metzler M, Millot F and Schleyer E: Pharmacology and pharmacokinetics of imatinib in pediatric patients. Expert Rev Clin Pharmacol 11(3): 219-231, 2018. PMID: 29076384, doi: 10.1080/17512433.2018.1398644

12 Millot F, Guilhot J, Baruchel A, Petit A, Leblanc T, Bertrand Y, Mazingue F, Lutz P, Vérité C, Berthou C, Galambrun C, Nicolas Sirvent, Yacouben K, Chastagner P, Gandemer V, Reguerre Y, Couillault G, Khalifeh T and Rialland F: Growth deceleration in children treated with imatinib for chronic myeloid leukaemia. Eur J Cancer 50(18): 3206-3211, 2014. PMID: 25459396, doi: $10.1016 /$ j.ejca.2014.10.007

13 Mehlig LM, Garve C, Tauer JT, Suttorp M and Bauer A: Inhibitory effects of imatinib on vitamin $\mathrm{D}(3)$ synthesis in human keratinocytes. Mol Med Rep 11: 3143-3147, 2015. PMID: 25501030, doi: 10.3892/mmr.2014.3074

14 Choeyprasert W, Yansomdet T, Natesirinilkul R, Wejaphikul K and Charoenkwan P: Adverse effects of imatinib in children with chronic myelogenous leukaemia. Pediatr Int 59(3): 286-292, 2017. PMID: 27541072, doi: 10.1111/ped.13136

15 Rousselot P, Huguet F, Rea D, Legros L, Cayuela JM, Maarek O, Blanchet O, Marit G, Gluckman E, Reiffers J, Gardembas M and Mahon FX: Imatinib mesylate discontinuation in patients with chronic myelogenous leukemia in complete molecular remission for more than 2 years. Blood 109(1): 58-60, 2007. PMID: 16973963, doi: 10.1182/blood-2006-03-011239
16 Ross DM, Branford S, Seymour JF, Schwarer AP, Arthur C, Yeung DT, Dang P, Goyne JM, Slader C, Filshie RJ, Mills AK, Melo JV, White DL, Grigg AP and Hughes TP: Safety and efficacy of imatinib cessation for CML patients with stable undetectable minimal residual disease: results from the TWISTER study. Blood 122(4): 515-522, 2013. PMID: 23704092, doi: 10.1182/blood-2013-02-483750

17 Takahashi N, Tauchi T, Kitamura K, Miyamura K, Saburi Y, Hatta Y, Miyata Y, Kobayashi S, Usuki K, Matsumura I, Minami Y, Usui N, Fukuda T, Takada S, Ishikawa M, Fujimaki K, Gomyo H, Sasaki O, Ohishi K, Miyake T, Imai K, Suzushima H, Mitsui H, Togitani K, Kiguchi T, Atsuta Y, Ohtake S, Ohnishi K, Kobayashi Y, Kiyoi H, Miyazaki Y, Naoe T and Japan Adult Leukemia Study Group: Deeper molecular response is a predictive factor for treatment-free remission after imatinib discontinuation in patients with chronic phase chronic myeloid leukemia: the JALSG-STIM213 study. Int J Hematol 107(2): 185-193, 2018. PMID: 28929332, doi: 10.1007/s12185-0172334-x

18 Etienne G, Guilhot J, Rea D, Rigal-Huguet F, Nicolini F, Charbonnier A, Guerci-Bresler A, Legros L, Varet B, Gardembas M, Dubruille V, Tulliez M, Noel MP, Ianotto JC, Villemagne B, Carré M, Guilhot F, Rousselot P and Mahon FX: Long-Term follow-up of the French Stop Imatinib (STIM1) study in patients with chronic myeloid leukemia. J Clin Oncol 35(3): 298-305, 2017. PMID: 28095277, doi: 10.1200/JCO.2016.68.2914

19 Tanizawa A: Optimal management for pediatric chronic myeloid leukaemia. Pediatr Int 58(3): 171-179, 2016. PMID: 26646444, doi: $10.1111 /$ ped. 12876

20 Cortes J and Kantarjian H: How I treat newly diagnosed chronic phase CML. Blood 120(7): 1390-1397, 2012. PMID: 22613793, doi: 10.1182/blood-2012-03-378919

21 Deenik W, Janssen JJ, van der Holt B, Verhoef GE, Smit WM, Kersten MJ, Daenen SM, Verdonck LF, Ferrant A, Schattenberg AV, Sonneveld P, van Marwijk Kooy M, Wittebol S, Willemze R, Wijermans PW, Beverloo HB, Löwenberg B, Valk PJ, Ossenkoppele GJ and Cornelissen JJ: Efficacy of escalated imatinib combined with cytarabine in newly diagnosed patients with chronic myeloid leukemia. Haematologica 95(6): 914-921, 2010. PMID: 20015886, doi: 10.3324/haematol.2009.016766

22 Chisick L, Seftel M and Kumar R: Algorithm for initial management of priapism in chronic myeloid leukaemia. Br J Haematol 159(2): 250-251, 2012. PMID: 22924590, doi: $10.1111 /$ bjh. 12015

23 Veljković D, Kuzmanović M, Mićić D and Šerbić-Nonković O: Leukapheresis in management hyperleukocytosis induced complications in two pediatric patients with chronic myelogenous leukaemia. Transfus Apher Sci 46(3): 263-267, 2012. PMID: 22480956, doi: 10.1016/j.transci.2012.03.012

24 Castagnetti M, Sainati L, Giona F, Varotto S, Carli M and Rigamonti W: Conservative management of priapism secondary to leukaemia. Pediatr Blood Cancer 51(3): 420-423, 2008. PMID: 18506758, doi: 10.1002/pbc.21628

25 Rodgers $\mathrm{R}$, Latif $\mathrm{Z}$ and Copland $\mathrm{M}$ : How I manage priapism in chronic myeloid leukaemia patients. Br J Haematol 158(2): 155164, 2012. PMID: 22571386, doi: 10.1111/j.1365-2141.2012. 09151.x

26 Salas DG, Glauche I, Tauer JT, Thiede C and Suttorp M: Can prognostic scoring systems for chronic myeloid leukaemia as established in adults be applied to pediatric patients? Ann 
Hematol 94(8): 1363-1371, 2015. PMID: 25894600, doi: $10.1007 / \mathrm{s} 00277-015-2367-2$

27 Giona F, Santopietro M, Menna G, Putti MC, Micalizzi C, Santoro N, Ziino O, Mura R, Ladogana S, Iaria G, Sau A, Burnelli R, Vacca N, Bernasconi S, Consarino C, Petruzziello F, Moleti ML, Biondi A, Locatelli $\mathrm{F}$ and Foà R: Real-life management of children and adolescents with chronic myeloid leukaemia: The Italian experience. Acta Haematol 140(2): 105111, 2018. PMID: 30227398, doi: 10.1159/000491546

28 Andolina JR, Neudorf SM and Corey SJ: How I treat childhood CML. Blood 119(8): 1821-1830, 2012. PMID: 22210880, doi: 10.1182/blood-2011-10-380774
29 Hijiya N, Schultz KR, Metzler M, Millot F and Suttorp M: Paediatric chronic myeloid leukaemia is a unique disease that requires a different approach. Blood 127(4): 392-399, 2016. PMID: 26511135, doi: 10.1182/blood-2015-06-648667

Received December 27, 2018 Revised January 28, 2019 Accepted January 31, 2019 